\section{Kidney \\ Blood Pressure Research}

\title{
Association of Bone Mineral Density with Albuminuria and Estimated Glomerular Filtration Rate : The Dong-gu Study
}

\author{
Seong-Woo Choi ${ }^{a}$ Hye-Yeon Kim ${ }^{b}$ Hye-Ran Ahnc Young-Hoon Lee ${ }^{d}$ Sun-Seog \\ Kweonce Jin-Su Choic Jung-Ae Rheec Hae-Sung Nam ${ }^{f}$ Seul-Ki Jeong ${ }^{\mathrm{g}}$ \\ Kyeong-Soo Park ${ }^{b}$ So-Yeon Ryu ${ }^{a}$ Hye-Rim Song ${ }^{c}$ Min-Ho Shin ${ }^{c}$ \\ aDepartment of Preventive Medicine, Chosun University Medical School, 375, Seosuk-dong, Gwangju \\ 501-759, Republic of Korea; bepartment of Preventive Medicine, Seonam University College of \\ Medicine, 720, Kwangchi-dong, Namwon, Jeollabukdo 590-711, Republic of Korea; 'Department of \\ Preventive Medicine, Chonnam National University Medical School, 5, Hak-1-dong, Dong-gu, Gwangju \\ 501-746, Republic of Korea; dDepartment of Preventive Medicine \& Institute of Wonkwang Medical \\ Science, Wonkwang University College of Medicine, 460, Iksandae-ro, Iksan, Jeollabukdo 570-749, \\ Republic of Korea; eJeonnam Regional Cancer Center, Chonnam National University Hwasun Hospital, \\ 160, Ilsim-ri, Hwasun-eup, Hwasun-gun, Jeollanamdo 519-809, Republic of Korea; 'Department of \\ Preventive Medicine, Chungnam National University College of Medicine, 6, Moonwha-1-dong, \\ Daejeon 301-747, Republic of Korea; ${ }^{D}$ Department of Neurology \& Research Institute of Clinical \\ Medicine, Chonbuk National University Medical School \& Hospital, San 2-20, Geumam-dong, Jeonju, \\ Jeollabukdo 561-180, Republic of Korea
}

\section{Key Words}

Albuminuria • Estimated glomerular filtration rate $•$ Bone mineral denstiy

\begin{abstract}
Background: Kidney dysfunction and albuminuria may be associated with BMD. However, little evidence has been reported on relationships between BMD and eGFR and albuminuria. Methods: A total of 8,992 subjects aged 50 years or older participated in a survey conducted. Participants had their lumbar spine and femoral neck BMD measured by a Lunar Prodigy bone densitometer (GE, Madison, WI). Kidney function was assessed using MDRD eGFR and diagnosis of albuminuria was based on albumin-creatinine ratio. Results: ACR was negatively associated with lumbar spine and femur neck BMD in females (lumbar spine: $1.001,0.988$, 0.974 and $0.979 \mathrm{~g} / \mathrm{cm}^{2}, \mathrm{p}<0.001$; femur neck: 0.796, $0.790,0.783$ and $0.782 \mathrm{~g} / \mathrm{cm}^{2}, \mathrm{p}=$ 0.002 ), but not in males, after adjusting for covariates. Additionally, eGFR was shown to be negatively associated with lumbar spine BMD after adjusting for covariates (male: 1.181, 1.166,
\end{abstract}




\section{Kidney \\ Blood Pressure Research}

Kidney Blood Press Res 2013;37:132-141

DOI: 10.1159/000350067

Published onIIne: April 24, 2013

(C) 2013 S. Karger AG, Basel

www.karger.com/kbr

Choi/Kim/Ahn/Lee/Kweon/Choi/Rhee/Nam/Jeong/Park/Ryu/Song/Shin: Association of BMD with Albuminuria and eGFR

1.152 and $1.149 \mathrm{~g} / \mathrm{cm}^{2}, \mathrm{p}=0.001$; female: 0.997, 0.980, 0.979 and $0.982 \mathrm{~g} / \mathrm{cm}^{2}, \mathrm{p}=0.005$ ), but demonstrated no association with femur BMD. Conclusions: ACR in females was negatively associated with lumbar spine and femur neck BMD, but not in males. eGFR was negatively associated with lumbar spine BMD in both males and females.

Copyright (c) 2013 S. Karger AG, Basel

\section{Introduction}

Approximately $20 \%$ of people aged $\geq 65$ years in the US exhibit moderate or severe kidney dysfunction [1]. Moreover, decreased renal function is associated with cardiovascular mortality and morbidity [2,3] and is known to disturb bone and mineral metabolism [4]. Patients with end-stage kidney disease (ESKD) have both a lower bone mineral density (BMD) and a higher risk of osteoporotic fractures [5, 6]. Furthermore, individuals with renal insufficiency may also exhibit reduced BMD as a result of vitamin D-parathyroid hormone (PTH) homeostasis and metabolic acidosis [7]. Previous studies have reported that kidney dysfunction is associated with BMD [8-13]. However, because of small sample sizes and the result that the associations disappeared after adjusting for key confounders, such as sex, age and weight, the significance of those findings is uncertain.

Albuminuria is associated with atherosclerosis, which is mediated by vascular endothelial damage [14]. Moreover, endothelial dysfunction plays a key role in the initiation and progression of atherosclerosis [15]. Endothelial dysfunction of the glomerular basement membrane can modify glomerular barrier permeability in the kidneys, leading to excretion of albumin into the urine [16]. Atherosclerotic vascular disease may also directly impact bone metabolism and contribute to the development of osteoporosis [17]. Atherosclerosis severity is inversely correlated with BMD, independent of age and body mass index (BMI) $[18,19]$. In addition, some medicines, including statins, concordantly enhance bone density and diminish atherogenesis [20]. However, little evidence has been reported on cause-andeffect relationships between BMD and albuminuria.

It is generally acknowledged that there are differences in the prevalence of osteoporosis between males and females [21]. Several studies have shown that postmenopausal women exhibit greater bone loss [22, 23] compared to men of the same age. Female gender is also considered a major risk factor for hip fracture in the general population [24].

Thus, in this study, BMD, the albumin-creatinine ratio (ACR) and estimated glomerular filtration rate (eGFR) were assessed and compared in Koreans aged $\geq 50$ years to expose gender differences therein.

\section{Materials and Methods}

\section{Study population}

The Dong-gu Study is an ongoing prospective study designed to investigate the prevalence, incidence, and risk factors for chronic disease in an urban population. Details on the study subjects and measurements performed were published previously [25]. National resident registration records were used to identify potential participants in the study. From 2007 to 2010, 34,040 eligible subjects aged $\geq 50$ years who resided in the Dong-gu district of Gwangju metropolitan city in South Korea were invited by telephone to participate in this study, and 9,260 subjects were enrolled (response rate: 27.2\%; 3,713 males and 5,547 females). After excluding 268 respondents who did not provide urinary samples or did not have their BMD measured, 8,992 subjects (3,602 men, 5,390 women) were included in the present analyses.

This study was conducted in accordance with the Declaration of Helsinki. The study protocol was approved by the institutional review board of Chonnam National University Hospital, and informed consent was obtained from each subject. 


\section{Kidney Blood Pressure Research}

Kidney Blood Press Res 2013;37:132-141

DOI: 10.1159/000350067

Published onlıne: April 24, 2013

(C) 2013 S. Karger AG, Basel

www.karger.com/kbr

Thoi/Kim/Ahn/Lee/Kweon/Choi/Rhee/Nam/Jeong/Park/Ryu/Song/Shin: Association of BMD with Albuminuria and eGFR

Trained examiners interviewed patients using a questionnaire that included items to assess cigarette use, alcohol consumption, physical activity, use of diabetes medications, use of hypertension medications, and menopausal status. Weight was measured to the nearest $0.1 \mathrm{~kg}$, with subjects dressed in light clothing, and height was measured to the nearest $0.1 \mathrm{~cm}$ in stocking feet. Venous blood samples and urinary specimens were collected from subjects following an overnight fast. Serum was separated on site and stored at $-70^{\circ} \mathrm{C}$ until ready for use. Urinary albumin and creatinine concentrations were measured by turbidimetric immunoassay and the Jaffe method [26] using a Hitachi-7600 analyzer (Hitachi Ltd., Tokyo, Japan).

\section{Kidney function}

Kidney function was assessed according to eGFR, which was calculated using the MDRD formula [27] as follows: $175 \times\left(\right.$ serum creatinine $\left.\mathrm{e}^{-1.154}\right) \times\left(\right.$ age $\left.^{-0.203}\right) \times 0.742$ [if female], expressing serum creatinine concentration in $\mathrm{mg} / \mathrm{dl}$. A diagnosis of albuminuria was based on ACR, which was calculated by dividing urinary albumin concentration $(\mu \mathrm{g})$ by urinary creatinine concentration $(\mathrm{mg})$.

$B M D$

Participants underwent measurement of lumbar spine and femoral neck BMDs with a Lunar Prodigy bone densitometer (GE, Madison, WI, USA). Lumbar spine BMD represented the average BMD of L1-L4. Daily phantom scans were performed each morning for proper quality control. All BMD scans were conducted by well-trained examiners using standardized procedures following the manufacturer's recommended protocols. Any scans comprising metal or other attenuating material in the region of interest as well as any scans of poor quality were discarded.

\section{Statistical analysis}

Data are presented as mean \pm standard deviation (SD) or percentages for categorical variables. All analyses were stratified by sex. Models 1 and 2 were adjusted for age, height, and BMI in men and women, respectively. Model 3 included the Model 1 variables plus smoking, alcohol intake, physical activity regimen, diabetes medication, hypertension medication, and log transformed ACR or log transformed eGFR in men. Finally, Model 4 included all of the Model 3 variables plus menopausal status in women. Analysis of covariance by the models mentioned above was used to compare mean lumbar spine and right femoral neck BMD according to eGFR and ACR quartiles. Statistical significance was set at $p<0.05$. Statistical analyses were performed using SPSS software package version 15.0 (SPSS Inc., Chicago, IL, USA).

\section{Results}

\section{Baseline characteristics of the subjects}

The baseline characteristics of the subjects are listed in Table 1. Age, height, weight, lumbar spine BMD, and femoral neck BMD were all higher in males than those in females. BMI was higher in females than that in males. Male subjects were more likely to smoke, drink alcohol, be physically active, and take diabetes medication than those in females.

\section{Characteristics of the subjects according to ACR and eGFR quartiles}

Table 2 shows the characteristics of the subjects according to ACR quartiles. Height and eGFR tended to be lower, whereas age and BMI tended to be higher with increased ACR in both male and female subjects. More males tended to report taking diabetes medication with increased ACR. More females tended to report taking hypertension medication and consuming relatively less alcohol, as well as being less physically active, and have postmenopausal status with increased ACR, as compared to male subjects.

Table 3 lists the subjects' characteristics according to eGFR quartiles. Age, BMI, and taking hypertension medication tended to be lower with increased eGFR in both male and female subjects. Height and weight tended to be lower in females than in males, whereas ACR tended to be lower with increased eGFR in males than occurred in females. Furthermore, more females tended to report consuming greater amounts of alcohol and fewer females tended to report taking diabetes medication and to be of postmenopausal status with increased eGFR. 


\section{Kidney Blood Pressure Research}

Table 1. Baseline characteristics of subjects
Table 2. Characteristics of the subjects according to the ACR

\begin{tabular}{lccc}
\hline & Male & Female & $p$ \\
\hline$N(\%)$ & $3602(40.1)$ & $5390(59.9)$ & - \\
Age (years) & $66.2 \pm 8.0$ & $64.4 \pm 8.2$ & $<0.001$ \\
Height $(\mathrm{cm})$ & $165.9 \pm 5.7$ & $153.2 \pm 5.5$ & $<0.001$ \\
Weight $(\mathrm{kg})$ & $65.9 \pm 9.1$ & $57.8 \pm 8.0$ & $<0.001$ \\
BMI $\left(\mathrm{kg} / \mathrm{m}^{2}\right)$ & $23.9 \pm 2.8$ & $24.6 \pm 3.0$ & $<0.001$ \\
ACR $\left(\mu \mathrm{mg} / \mathrm{mg}^{2}\right.$ & $42.7 \pm 153.6$ & $37.6 \pm 146.5$ & 0.108 \\
eGFR $\left(\mathrm{m} \ell / \mathrm{min}\right.$ per $\left.1.73 \mathrm{~m}^{2}\right)$ & $65.4 \pm 12.3$ & $65.3 \pm 12.0$ & 0.882 \\
Lumbar BMD $\left(\mathrm{g} / \mathrm{cm}^{2}\right)$ & $1.2 \pm 0.2$ & $1.0 \pm 0.2$ & $<0.001$ \\
Femur neck BMD $\left(\mathrm{g} / \mathrm{cm}^{2}\right)$ & $0.9 \pm 0.1$ & $0.8 \pm 0.1$ & $<0.001$ \\
Smoking $(\%)$ & $882(24.5)$ & $98(1.8)$ & $<0.001$ \\
Alcohol intake $(\%)$ & $2893(80.5)$ & $2004(37.3)$ & $<0.001$ \\
Physically active $(\%)$ & $1380(38.5)$ & $1504(28.1)$ & $<0.001$ \\
Diabetes Medication $(\%)$ & $549(15.4)$ & $595(11.1)$ & $<0.001$ \\
Hypertension Medication $(\%)$ & $1258(35.2)$ & $1912(35.7)$ & 0.635 \\
\hline
\end{tabular}

All values are given as $n(\%)$ or mean \pm standard deviation.

BMI, body mass index; ACR, albumin creatinine ratio; eGFR, estimated glomerular filtration rate; BMD, bone mineral density

\begin{tabular}{|c|c|c|c|c|c|}
\hline ACR $(\mu \mathrm{g} / \mathrm{mg})$ & Q1 & Q2 & Q3 & Q4 & $P^{*}$ \\
\hline \multicolumn{6}{|l|}{ Male } \\
\hline$N(\%)$ & $997(27.7)$ & $819(22.7)$ & $839(23.3)$ & $947(26.3)$ & - \\
\hline $\operatorname{ACR}(\mu \mathrm{g} / \mathrm{mg})$ & $5.0 \pm 1.7$ & $9.9 \pm 1.5$ & $17.4 \pm 3.4$ & $133.5 \pm 280.3$ & $<0.001$ \\
\hline Age (years) & $64.4 \pm 7.6$ & $65.7 \pm 7.4$ & $66.8 \pm 7.9$ & $67.9 \pm 8.4$ & $<0.001$ \\
\hline Height $(\mathrm{cm})$ & $166.5 \pm 5.5$ & $166.3 \pm 5.8$ & $165.6 \pm 5.8$ & $165.2 \pm 5.5$ & $<0.001$ \\
\hline Weight $(\mathrm{kg})$ & $66.0 \pm 8.8$ & $65.6 \pm 9.4$ & $65.6 \pm 9.3$ & $66.4 \pm 9.2$ & 0.223 \\
\hline BMI $\left(\mathrm{kg} / \mathrm{m}^{2}\right)$ & $23.8 \pm 2.7$ & $23.7 \pm 2.8$ & $23.9 \pm 2.9$ & $24.3 \pm 2.9$ & $<0.001$ \\
\hline eGFR (ml/min per $\left.1.73 \mathrm{~m}^{2}\right)$ & $66.5 \pm 10.5$ & $66.4 \pm 11.1$ & $65.8 \pm 12.0$ & $62.8 \pm 14.6$ & $<0.001$ \\
\hline Smoking (\%) & $240(24.1)$ & $189(23.1)$ & $240(28.7)$ & $213(22.5)$ & 0.012 \\
\hline Alcohol intake (\%) & $805(80.9)$ & $630(77.0)$ & $695(83.2)$ & $763(80.7)$ & 0.015 \\
\hline Physically active (\%) & $396(39.9)$ & $308(37.7)$ & $309(37.1)$ & $367(39.0)$ & 0.622 \\
\hline Diabetes Medication (\%) & $73(7.4)$ & $90(11.1)$ & $116(14.0)$ & $270(28.8)$ & $<0.001$ \\
\hline Hypertension Medication (\%) & $300(30.2)$ & $274(33.9)$ & $265(32.0)$ & $419(44.7)$ & $<0.001$ \\
\hline \multicolumn{6}{|l|}{ Female } \\
\hline$N(\%)$ & $1251(23.2)$ & $1429(26.5)$ & $1409(26.1)$ & $1301(24.1)$ & - \\
\hline $\operatorname{ACR}(\mu \mathrm{g} / \mathrm{mg})$ & $5.0 \pm 1.8$ & $9.9 \pm 1.5$ & $17.5 \pm 3.4$ & $121.1 \pm 282.3$ & $<0.001$ \\
\hline Age (years) & $61.3 \pm 7.3$ & $63.5 \pm 7.7$ & $65.4 \pm 8.0$ & $67.3 \pm 8.5$ & $<0.001$ \\
\hline Height (cm) & $154.3 \pm 5.2$ & $153.7 \pm 5.4$ & $152.7 \pm 5.7$ & $152.1 \pm 5.6$ & $<0.001$ \\
\hline Weight $(\mathrm{kg})$ & $58.2 \pm 7.4$ & $57.8 \pm 7.7$ & $57.6 \pm 8.4$ & $57.8 \pm 8.3$ & 0.197 \\
\hline BMI $\left(\mathrm{kg} / \mathrm{m}^{2}\right)$ & $24.4 \pm 2.8$ & $24.4 \pm 2.8$ & $24.7 \pm 3.1$ & $24.9 \pm 3.1$ & $<0.001$ \\
\hline eGFR (ml/min per $\left.1.73 \mathrm{~m}^{2}\right)$ & $66.1 \pm 10.5$ & $66.4 \pm 11.1$ & $65.4 \pm 11.6$ & $63.3 \pm 14.3$ & $<0.001$ \\
\hline Smoking $(\%)$ & $22(1.8)$ & $23(1.5)$ & $32(2.3)$ & $22(1.7)$ & 0.494 \\
\hline Alcohol intake (\%) & $511(41.0)$ & $529(37.1)$ & $517(36.9)$ & $447(34.4)$ & 0.008 \\
\hline Physically active (\%) & $422(33.9)$ & $391(27.5)$ & $374(26.7)$ & $317(24.5)$ & $<0.001$ \\
\hline Diabetes Medication (\%) & $60(4.8)$ & $106(7.5)$ & $158(11.3)$ & $271(21.0)$ & $<0.001$ \\
\hline Hypertension Medication (\%) & $320(25.7)$ & $456(32.1)$ & $510(36.5)$ & $627(48.6)$ & $<0.001$ \\
\hline Postmenopause (\%) & $1164(93.6)$ & $1369(96.7)$ & $1363(97.6)$ & $1256(97.4)$ & $<0.001$ \\
\hline
\end{tabular}

Comparison of mean BMD according to ACR quartiles

Table 4 lists the mean values ( \pm standard error, SE) for lumbar spine and femoral neck $\mathrm{BMD}$ according to ACR quartiles. Lumbar spine and right femoral neck BMD values in male 


\section{Kidney Blood Pressure Research}

Table 3. Characteristics of the subjects according to the eGFR

\begin{tabular}{|c|c|c|c|c|c|}
\hline eGFR (me/min per $1.73 \mathrm{~m}^{2}$ ) & Q1 & Q2 & Q3 & Q4 & $P^{*}$ \\
\hline \multicolumn{6}{|l|}{ Male } \\
\hline$N(\%)$ & $905(24.9)$ & $915(25.2)$ & $892(24.6)$ & $908(25.0)$ & - \\
\hline eGFR $\left(\mathrm{m} \ell / \min\right.$ per $\left.1.73 \mathrm{~m}^{2}\right)$ & $4937 \pm 7.8$ & $60.8 \pm 1.8$ & $67.9 \pm 2.1$ & $79.7 \pm 6.7$ & $<0.001$ \\
\hline Age (years) & $68.2 \pm 8.1$ & $66.4 \pm 8.7$ & $66.2 \pm 7.9$ & $64.3 \pm 7.0$ & $<0.001$ \\
\hline Height $(\mathrm{cm})$ & $166.2 \pm 5.6$ & $166.1 \pm 5.5$ & $166.0 \pm 5.7$ & $165.4 \pm 5.8$ & 0.014 \\
\hline Weight (kg) & $67.4 \pm 8.6$ & $66.3 \pm 9.2$ & $65.7 \pm 9.3$ & $64.6 \pm 9.2$ & $<0.001$ \\
\hline BMI $\left(\mathrm{kg} / \mathrm{m}^{2}\right)$ & $24.4 \pm 2.6$ & $24.0 \pm 2.9$ & $23.8 \pm 2.9$ & $23.6 \pm 2.8$ & $<0.001$ \\
\hline $\mathrm{ACR}(\mu \mathrm{g} / \mathrm{mg})$ & $68.4 \pm 239.5$ & $31.7 \pm 88.8$ & $38.7 \pm 146.6$ & $33.2 \pm 90.1$ & $<0.001$ \\
\hline Smoking $(\%)$ & $197(23.0)$ & $178(23.3)$ & $234(24.0)$ & $273(27.2)$ & 0.129 \\
\hline Alcohol intake (\%) & $678(79.3)$ & $624(81.8)$ & $779(80.1)$ & $812(81.0)$ & 0.595 \\
\hline Physically active (\%) & $334(39.2)$ & $290(38.0)$ & $393(40.5)$ & $363(36.4)$ & 0.281 \\
\hline Diabetes Medication (\%) & $156(18.4)$ & $104(13.7)$ & $137(14.2)$ & $152(15.2)$ & 0.035 \\
\hline Hypertension Medication (\%) & $402(47.4)$ & $269(35.5)$ & $313(32.4)$ & $274(27.5)$ & $<0.001$ \\
\hline \multicolumn{6}{|l|}{ Female } \\
\hline$N(\%)$ & $1353(24.9)$ & $1359(25.1)$ & $1351(24.9)$ & $1346(24.8)$ & - \\
\hline eGFR (ml/min per $\left.1.73 \mathrm{~m}^{2}\right)$ & $50.7 \pm 7.3$ & $62.3 \pm 1.8$ & $70.1 \pm 2.6$ & $80.4 \pm 7.4$ & $<0.001$ \\
\hline Age (years) & $67.5 \pm 8.0$ & $65.2 \pm 7.5$ & $64.9 \pm 8.0$ & $59.3 \pm 6.9$ & $<0.001$ \\
\hline Height $(\mathrm{cm})$ & $152.9 \pm 5.6$ & $153.2 \pm 5.4$ & $152.9 \pm 5.8$ & $153.9 \pm 5.3$ & $<0.001$ \\
\hline Weight (kg) & $58.4 \pm 8.1$ & $57.7 \pm 8.0$ & $57.3 \pm 8.0$ & $57.9 \pm 7.7$ & 0.007 \\
\hline BMI $\left(\mathrm{kg} / \mathrm{m}^{2}\right)$ & $24.9 \pm 3.0$ & $24.6 \pm 3.0$ & $24.5 \pm 2.9$ & $24.4 \pm 2.9$ & $<0.001$ \\
\hline $\mathrm{ACR}(\mu \mathrm{g} / \mathrm{mg})$ & $65.5 \pm 248.0$ & $30.1 \pm 93.5$ & $27.6 \pm 78.7$ & $25.5 \pm 79.2$ & $<0.001$ \\
\hline Smoking (\%) & $33(2.4)$ & $24(1.8)$ & $18(1.4)$ & 21(1.7) & 0.375 \\
\hline Alcohol intake (\%) & $446(33.6)$ & $545(37.0)$ & $487(38.0)$ & $506(41.2)$ & 0.001 \\
\hline Physically active (\%) & $371(26.7)$ & $415(28.3)$ & $361(28.3)$ & $357(29.0)$ & 0.601 \\
\hline Diabetes Medication (\%) & $224(16.2)$ & $168(11.4)$ & $135(10.6)$ & $68(5.6)$ & $<0.001$ \\
\hline Hypertension Medication (\%) & $664(48.0)$ & $512(34.9)$ & $434(34.0)$ & $302(24.7)$ & $<0.001$ \\
\hline Postmenopause (\%) & $1367(99.2)$ & $1439(98.3)$ & $1217(95.5)$ & $1129(91.9)$ & $<0.001$ \\
\hline
\end{tabular}

subjects were not different according to ACR. Mean lumbar spine and right femoral neck BMD values in females decreased significantly with increasing ACR after adjusting for age, height, and BMI (Model 3) (lumbar spine: 0.999, 0.985, 0.973, and $0.984 \mathrm{~g} / \mathrm{cm}^{2} ; p<0.001$; femoral neck: $0.796,0.789,0.782$, and $0.784 \mathrm{~g} / \mathrm{cm}^{2} ; p=0.002$ ). These significant differences did not disappear after additionally adjusting for other covariates (Model 4) (lumbar spine: $1.001,0.988,0.974$, and $0.979 \mathrm{~g} / \mathrm{cm}^{2} ; p<0.001$; femoral neck: $0.796,0.790,0.783$, and 0.782 $\left.\mathrm{g} / \mathrm{cm}^{2}, p=0.002\right)$.

\section{Comparison of mean BMD according to eGFR quartiles}

Table 5 lists the mean values $( \pm$ SE) for lumbar spine and femoral neck BMD according to eGFR quartiles. Lumbar BMD decreased significantly with increased eGFR after adjusting for age, height, and BMI in male subjects (Model 1) $\left(1.182,1.166,1.152\right.$, and $1.147 \mathrm{~g} / \mathrm{cm}^{2} ; p$ $<0.001)$, and this significant difference did not disappear after further adjusting for other confounding factors (Model 2) $\left(1.181,1.166,1.152\right.$, and $\left.1.149 \mathrm{~g} / \mathrm{cm}^{2} ; p=0.001\right)$. Mean lumbar BMD values in female subjects decreased significantly with increased eGFR after adjusting for age, height, and BMI (Model 3) $\left(0.998,0.978,0.982\right.$, and $0.971 \mathrm{~g} / \mathrm{cm}^{2} ; p=0.002$ ). This significant difference also did not disappear after further adjusting for other confounding factors (Model 4), (0.997, 0.980, 0.979, and $\left.0.982 \mathrm{~g} / \mathrm{cm}^{2} ; p=0.015\right)$. However, femoral neck BMD values did not significantly differ between eGFR quartiles. 


\section{Kidney \\ Blood Pressure Research}

Kidney Blood Press Res 2013;37:132-141

DOI: 10.1159/000350067

Published onlıne: April 24, 2013

(C) 2013 S. Karger AG, Basel

www.karger.com/kbr

Choi/Kim/Ahn/Lee/Kweon/Choi/Rhee/Nam/Jeong/Park/Ryu/Song/Shin: Association of BMD with Albuminuria and eGFR

Table 4. Comparison of mean BMD according to the ACR

\begin{tabular}{|c|c|c|c|c|c|}
\hline & \multirow{2}{*}{$\begin{array}{c}\text { ACR } \\
(\mu \mathrm{g} / \mathrm{mg})\end{array}$} & \multicolumn{2}{|c|}{ Male } & \multicolumn{2}{|c|}{ Female } \\
\hline & & Model $1^{*}$ & Model $2^{\dagger}$ & Model $3^{* *}$ & Model $4^{+\dagger}$ \\
\hline \multirow{5}{*}{ Lumbar (L1-L4) } & Q1 & $1.161(0.006)$ & $1.163(0.006)$ & $0.999(0.004)$ & $1.001(0.004)$ \\
\hline & Q2 & $1.157(0.007)$ & $1.161(0.007)$ & $0.985(0.004)$ & $0.988(0.004)$ \\
\hline & Q3 & $1.155(0.006)$ & $1.158(0.006)$ & $0.973(0.004)$ & $0.974(0.004)$ \\
\hline & Q4 & $1.168(0.006)$ & $1.161(0.006)$ & $0.984(0.004)$ & $0.979(0.004)$ \\
\hline & $p$ & 0.469 & 0.953 & $<0.001$ & $<0.001$ \\
\hline \multirow{5}{*}{ Femur neck } & Q1 & $0.884(0.004)$ & $0.884(0.004)$ & $0.796(0.003)$ & $0.796(0.003)$ \\
\hline & Q2 & $0.877(0.004)$ & $0.880(0.004)$ & $0.789(0.003)$ & $0.790(0.003)$ \\
\hline & Q3 & $0.880(0.004)$ & $0.882(0.004)$ & $0.782(0.003)$ & $0.783(0.003)$ \\
\hline & Q4 & $0.882(0.004)$ & $0.880(0.004)$ & $0.784(0.003)$ & $0.782(0.003)$ \\
\hline & $p$ & 0.724 & 0.834 & 0.002 & 0.002 \\
\hline
\end{tabular}

All values are given as Mean (Standard Error). BMD, bone mineral density; ACR, albumin creatinine ratio. * Adjusted by age, height, and BMI. †Adjusted by age, height, BMI, smoking, alcohol intake, physically active, diabetes medication, hypertension medication, and $\ln (\mathrm{eGFR}) .{ }^{* *}$ Adjusted by age, height, and BMI. ††Adjusted by age, height, BMI, smoking, alcohol intake, physically active, diabetes medication, hypertension medication, $\ln (\mathrm{eGFR})$, and postmenopause.

Table 5. Comparison of mean BMD according to the eGFR

\begin{tabular}{|c|c|c|c|c|c|}
\hline & \multirow{2}{*}{$\begin{array}{c}\mathrm{eGFR}(\mathrm{m} \ell / \mathrm{min} \\
\left.\operatorname{per} 1.73 \mathrm{~m}^{2}\right)\end{array}$} & \multicolumn{2}{|c|}{ Male } & \multicolumn{2}{|c|}{ Female } \\
\hline & & Model $1^{*}$ & Model $2^{+}$ & Model $3^{* *}$ & Model $4^{\dagger \dagger}$ \\
\hline \multirow{5}{*}{ Lumbar (L1-L4) } & Q1 & $1.182(0.006)$ & $1.181(0.007)$ & $0.998(0.004)$ & $0.997(0.004)$ \\
\hline & Q2 & $1.166(0.007)$ & $1.166(0.007)$ & $0.978(0.004)$ & $0.980(0.004)$ \\
\hline & Q3 & $1.152(0.006)$ & $1.152(0.006)$ & $0.982(0.004)$ & $0.979(0.004)$ \\
\hline & Q4 & $1.147(0.006)$ & $1.149(0.006)$ & $0.971(0.004)$ & $0.982(0.004)$ \\
\hline & $p$ & $<0.001$ & 0.001 & 0.002 & 0.005 \\
\hline \multirow{5}{*}{ Femur neck } & Q1 & $0.887(0.004)$ & $0.889(0.004)$ & $0.788(0.003)$ & $0.788(0.003)$ \\
\hline & Q2 & $0.876(0.004)$ & $0.876(0.004)$ & $0.786(0.003)$ & $0.786(0.003)$ \\
\hline & Q3 & $0.883(0.004)$ & $0.883(0.004)$ & $0.789(0.003)$ & $0.787(0.003)$ \\
\hline & Q4 & $0.877(0.004)$ & $0.878(0.004)$ & $0.788(0.003)$ & $0.788(0.003)$ \\
\hline & $p$ & 0.170 & 0.126 & 0.888 & 0.884 \\
\hline
\end{tabular}

All values are given as Mean (Standard Error). BMD, bone mineral density; eGFR, estimated glomerular filtration rate. ${ }^{*}$ Adjusted by age, height, and BMI. †Adjusted by age, height, BMI, smoking, alcohol intake, physically active, diabetes medication, hypertension medication, and $\ln$ (ACR). ${ }^{* *}$ Adjusted by age, height, and BMI. ${ }^{\dagger}$ Adjusted by age, height, BMI, smoking, alcohol intake, physically active, diabetes medication, hypertension medication, $\ln (\mathrm{ACR})$, and postmenopause.

\section{Discussion}

We investigated whether lumbar spine and femoral neck BMD were associated with ACR and eGFR in Koreans aged $\geq 50$ years. The data suggest that ACR was negatively associated with lumbar spine and femoral neck BMD in females, but not in males, after adjusting for age, weight, and other covariates.

Only one other study has examined the relationship between ACR and BMD in the general population. In the Troms $\varnothing$ study, Jørgensen et al. [28] followed 4,497 subjects aged 55-74 years old for an average of 8.4 years and examined whether elevated ACRs were associated with non-vertebral fractures. Those researchers measured initial BMD at the wrist by single X-ray absorptiometry and analyzed the associations between BMD and log transformed ACR. They reported that BMD was negatively associated with log transformed ACR, similar to the data presented in our study. 


\section{Kidney Blood Pressure Research}

Kidney Blood Press Res 2013;37:132-141

\begin{tabular}{l|l}
\hline DOI: 10.1159/000350067 & (C) 2013 S. Karger AG, Basel
\end{tabular}

Published onlıne: April 24, 2013

www.karger.com/kbr

Choi/Kim/Ahn/Lee/Kweon/Choi/Rhee/Nam/Jeong/Park/Ryu/Song/Shin: Association of BMD with Albuminuria and eGFR

Endothelial dysfunction of the glomerular basement membrane can modify glomerular barrier permeability in the kidneys, leading to excretion of albumin into the urine [16]. Therefore, albuminuria is a marker of endothelial dysfunction, plays a key role in the initiation and progression of atherosclerosis [15], and is associated with increased levels of inflammatory markers [29]. One of the explanations that has been proposed for the association between albuminuria and osteoporosis is that albuminuria is associated with reduced bone blood flow, resulting in a decreased rate of bone remodeling and the development of osteoporosis [30]. Moreover, some investigators have found a positive relationship between ACR and PTH [28]. When serum calcium level is low, PTH level rises, which may promote osteoclast-mediated bone resorption.

In this study, ACR was associated with BMD in female subjects only. It is well-known that there are gender differences in bone density. Furthermore, BMD decreases linearly in women with age after menopause at a 1.7-fold faster rate than in their male counterparts [31]. Gender differences in BMD are multifactorial, but hormones seem to play an important role. Estrogens exert beneficial effects on plasma lipid and lipoprotein concentrations and reduce atherosclerosis [32]. Estrogen deficiency in females following menopause contributes to a relatively higher presence of osteoporosis in women compared with men [33]. In addition, estrogen was negatively correlated with ACR among females with type 2 diabetes [32]. Therefore, ACR might be associated with mediation of BMD by estrogen in females.

According to the present data, eGFR was not associated with femoral neck BMD and was negatively associated with lumbar spine BMD. Previous studies have investigated the associations between renal insufficiency and BMD, but the results were conflicting [8-13, 3436]. A few small studies have indicated that renal insufficiency is related to low bone mass [8-13], but data from more extensive studies have indicated that such an association could be explained by confounding factors, primarily sex, age, and weight [34-36].

Hsu et al. [35] analyzed 13,848 adults aged $\geq 20$ years who took part in the Third National Health and Nutrition Examination Survey. Proximal femoral BMD was measured using dual energy X-ray absorptiometry (DXA), and kidney function was assessed according to serum creatinine, blood urea nitrogen and Cockcroft-Gault equation creatinine clearance. They reported that chronic renal insufficiency was not associated with femoral BMD after adjusting for confounding factors. In the Cardiovascular Health Study (1,519 participants), researchers investigated whether kidney function, as assessed by cystatin-C levels, was associated with BMD, and reported that cystatin-C is related to annual changes in BMD, but not with initial femur or total hip BMD [34]. However, as a critical limitation of their study, cystatin-C level was determined 2 years prior to the BMD measurements. In the Osteoporotic Fractures in Men (MrOS) study [36], investigators followed 404 elderly male subjects for an average of 4.4 years and observed a significant association between cystatin- $C$ and annual change in total hip BMD. However, no difference in baseline total hip BMD was observed according to quartiles of cystatin-C concentration $(p=0.90)$. In these studies, kidney function was not associated with BMD, similar to the present study.

We estimated kidney function according to MDRD eGFR, rather than by using cystatin-C. MDRD eGFR is based on serum creatinine levels, which are influenced, in part, by muscle mass, whereas cystatin-C level does not depend on age, sex, or muscle mass. While it is recognized that serum cystatin-C is superior to serum creatinine as a marker of kidney function [37], whether cystatin-C is a better predictor of GFR than MDRD eGFR remains controversial [38, 39]. We reanalyzed the present data after adjusting for lean body mass, but there was little effect on previously observed outcomes (data not shown).

In this study, decreased eGFR was associated with increased lumbar spine BMD. This is contrary to the previous notion that patients with chronic renal insufficiency may have reduced BMD as a result of abnormalities in acid-base and vitamin D- PTH homeostasis [35]. The reason why eGFR is negatively associated with lumbar spine BMD remains unclear, although several explanations have been proposed. First, the previous notion that patients with chronic renal insufficiency may have reduced BMD as a result of abnormalities in acidbase and vitamin D- PTH homeostasis arose from a study on patients with ESRD. Advanced 


\section{Kidney \\ Blood Pressure Research}

Kidney Blood Press Res 2013;37:132-141

\begin{tabular}{l|l}
\hline DOI: $10.1159 / 000350067$ & C 2013 S. Karger AG, Basel
\end{tabular}

Published onlıne: April 24, 2013

www.karger.com/kbr

Choi/Kim/Ahn/Lee/Kweon/Choi/Rhee/Nam/Jeong/Park/Ryu/Song/Shin: Association of BMD with Albuminuria and eGFR

kidney dysfunction in patients with ESRD is associated with reduced BMD; patients with ESRD also exhibit elevated PTH, chronic acidosis, and bone turnover abnormalities [6,9]. However, an association between renal insufficiency and BMD was not shown in mild or moderate patients with chronic kidney disease (CKD) [34-36]. Interestingly, in the study that utilized data from NHANES III [40], individuals with osteoporosis (BMD T-score $>2.5 \mathrm{SD}$ ) had a much higher prevalence of mild to moderate CKD, whereas osteopenia (BMD T-score 1-2.5 SD) was observed in patients with severe CKD. Second, findings should be interpreted in the context of the study design. The subjects of the present study underwent measurement of lumbar spine and femoral neck BMD, whereas the subjects of the NHANES III, Cardiovascular Health, and MrOS studies underwent measurements of femoral neck and/or total hip BMD [34-36]. Third, measuring BMD using DXA entails certain limitations, as the technique utilizes attenuation of radiation in bone or soft tissue. Thus, anything within the radiation path can lead to an overestimation of BMD, such as arthritic conditions, scoliosis, aortic calcification, or peritoneal fluid [41]. Moreover, patients with CKD have poor bone quality, which cannot be measured by absorptiometry, including abnormal micro-architecture, mineralization density, crystal deposition in the bone matrix or abnormalities in the matrix itself [41].

It is well-known that BMI is associated with osteoporosis $[42,43]$. In the present study, BMD was positively associated with BMI (data not shown). Two hypotheses have been proposed to explain the relationship between BMI and osteoporosis. First, body fat provides indirect protection from bone loss by mediating the peripheral conversion of adrenal steroids to metabolically active estrogen [44]. Second, heavy individuals in early adulthood tend to reach a higher peak BMD than thinner individuals, leading to the development of higher BMD [45].

This study had several limitations. First, no direct measurement of GFR was obtained, the gold standard of which is insulin clearance, but this was not feasible in a large epidemiologic study. Second, levels of drugs known to influence bone metabolism (such as estrogens, bisphosphonates, glucocorticoids, and thiazides) were not measured. Some medicines, including statins, concordantly enhance bone density and diminish atherogenesis [20]. Third, levels of potential mediators of bone loss, such as calcium, phosphorus, vitamin D, or PTH, were not determined.

Despite these limitations, this study contributes greatly to the current knowledge concerning the associations between ACR or eGFR and BMD in a large, community-based population.

\section{Conclusion}

In conclusion, ACR was negatively associated with lumbar spine and femoral neck BMD in females, but not in males, after adjusting for age, height, BMI and other covariates. In addition, eGFR was negatively associated with lumbar spine BMD in both males and females after adjusting for the same confounding factors, but showed no association with femoral BMD.

\section{Conflict of Interests}

None declared. 


\section{Kidney \\ Blood Pressure Research}

Choi/Kim/Ahn/Lee/Kweon/Choi/Rhee/Nam/Jeong/Park/Ryu/Song/Shin: Association of BMD with Albuminuria and eGFR

\section{References}

1 Coresh J, Astor B, Greene T, Eknoyan G, Levey A: Prevalence of chronic kidney disease and decreased kidney function in the adult US population: Third National Health and Nutrition Examination Survey. Am J Kidney Dis 2003;41:1-12.

2 de Leeuw PW, Thijs L, Birkenhager WH, Voyaki SM, Efstratopoulos AD, Fagard RH, Leonetti G, Nachev C, Petrie JC, Rodicio JL, Rosenfeld JJ, Sarti C, Staessen JA: Prognostic Significance of Renal Function in Elderly Patients with Isolated Systolic Hypertension: Results from the Syst-Eur Trial. J Am Soc Nephrol 2002;13:2213-2222.

3 Shlipak MG, Simon JA, Grady D, Lin F, Wenger NK, Furberg CD: Renal insufficiency and cardiovascular events in postmenopausal women with coronary heart disease. J Am Coll Cardiol 2001;38:705-711.

4 Gal-Moscovici A, Sprague SM: Endocrinology and Dialysis Jean L. Holley, Series Editor: Osteoporosis and Chronic Kidney Disease. Semin Dial 2007;20:423-430.

-5 Stehman-Breen C: Bone Mineral Density Measurements in Dialysis Patients. Semin Dial 2001;14:228-229.

6 Alem AM, Sherrard DJ, Gillen DL, Weiss NS, Beresford SA, Heckbert SR, Wong C, Stehman-Breen C: Increased risk of hip fracture among patients with end-stage renal disease. Kidney Int 2000;58:396-399.

7 Pitts TO, Piraino BH, Mitro R, Chen TC, Serge GV, Greenberg A, Puschett JB: Hyperparathyroidism and 1,25-Dihydroxyvitamin D Deficiency in Mild, Moderate, and Severe Renal Failure. J Clin Endocrinol Metab 1988;67:876-881.

8 Buchanan J, Myers C, Greer R: Effect of declining renal function on bone density in aging women. Calcif Tissue Int 1988;43:1-6.

-9 Rix M, Andreassen H, Eskildsen P, Langdahl B, Olgaard K: Bone mineral density and biochemical markers of bone turnover in patients with predialysis chronic renal failure. Kidney Int 1999;56:1084-1093.

$>10$ Yendt ER, Cohanim M, Jarzylo S, Jones G, Rosenberg G: Reduced creatinine clearance in primary osteoporosis in women. J Bone Miner Res 1993;8:1045-1052.

11 Yendt ER, Cohanim M, Jarzylo S, Jones G, Rosenberg G: Bone mass is related to creatinine clearance in normal elderly women. J Bone Miner Res 1991;6:1043-1050.

12 Bianchi ML, Colantonio G, Montesano A, Trevisan C, Ortolani S, Rossi R, Buccianti G: Bone mass status in different degrees of chronic renal failure. Bone 1992;13:225-228.

13 Sherman SS, Tobin JD, Hollis BW, Gundberg CM, Roy TA, Plato CC: Biochemical parameters associated with low bone density in healthy men and women. J Bone Miner Res 1992;7:1123-1130.

14 Stehouwer CDA: Endothelial dysfunction in diabetic nephropathy: state of the art and potential significance for non-diabetic renal disease. Nephrol Dial Transplant 2004;19:778-781.

15 Stehouwer CDA, Smulders YM: Microalbuminuria and Risk for Cardiovascular Disease: Analysis of Potential Mechanisms. J Am Soc Nephrol 2006;17:2106-2111.

16 Deen WM: What determines glomerular capillary permeability? J Clin Inv 2004;114:1412-1414.

17 Bagger YZ, TankÓ LB, Alexandersen P, Qin G, Christiansen C, The Prospective Epidemiological Risk Factors Study G: Radiographic measure of aorta calcification is a site-specific predictor of bone loss and fracture risk at the hip. J Int Med 2006;259:598-605.

18 Peter von der R, Marc Allan H, Christian H: The association between low bone mass at the menopause and cardiovascular mortality. Am J Med 1999;106:273-278.

19 Tanko LB, Bagger YZ, Christiansen C: Low bone mineral density in the hip as a marker of advanced atherosclerosis in elderly women. Calcif Tissue Int 2003;73:15-20.

20 Hamerman D: Osteoporosis and atherosclerosis: biological linkages and the emergence of dual-purpose therapies. QJM 2005;98:467-484.

21 Melton LJ, Atkinson EJ, O'Connor MK, O'Fallon WM, Riggs BL: Bone Density and Fracture Risk in Men. J Bone Miner Res 1998;13:1915-1923.

22 Guthrie JR, Ebeling PR, Hopper JL, Barrett-Connor E, Dennerstein L, Dudley EC, Burger HG, Wark JD: A Prospective Study of Bone Loss in Menopausal Australian-Born Women. Osteoporos Int 1998;8:282-290.

-23 Sowers M, Crutchfield M, Bandekar R, Randolph JF, Shapiro B, Schork MA, Jannausch M: Bone Mineral Density and Its Change in Pre- and Perimenopausal White Women: The Michigan Bone Health Study. J Bone Miner Res 1998;13:1134-1140.

24 Stehman-Breen CO, Sherrard DJ, Alem AM, Gillen DL, Heckbert SR, Wong CS, Ball A, Weiss NS: Risk factors for hip fracture among patients with end-stage renal disease. Kidney Int 2000;58:2200-2205. 


\section{Kidney \\ Blood Pressure Research}

Kidney Blood Press Res 2013;37:132-141

\begin{tabular}{l|l}
\hline DOI: $10.1159 / 000350067$ & (C) 2013 S. Karger AG, Basel
\end{tabular}

Published onlıne: April 24, 2013

www.karger.com/kbr

Choi/Kim/Ahn/Lee/Kweon/Choi/Rhee/Nam/Jeong/Park/Ryu/Song/Shin: Association of BMD with Albuminuria and eGFR

25 Seong-Woo C, Hye-Yeon K, Young-Hoon L, So-Yeon R, Sun-Seog K, Jung-Ae R, Jin-Su C, Min-Ho S: eGFR is associated with subclinical atherosclerosis independent of albuminuria: The Dong-gu Study. Atherosclerosis 2010;212:661-667.

-26 Lustgarten JA, Wink RE: Simple rapid kinetic method for serum creatinine measurement. Clin Chem 1972;18:1419.

27 Levey AS, Coresh J, Greene T, Stevens LA, Zhang Y, Hendriksen S, Kusek JW, Van Lente F: Using Standardized Serum Creatinine Values in the Modification of Diet in Renal Disease Study Equation for Estimating Glomerular Filtration Rate. Ann Int Med 2006;145:247-254.

-28 JØrgensen L, Jenssen T, Ahmed L, Bjornerem A, Joakimsen R, Jacobsen BK: Albuminuria and Risk of Nonvertebral Fractures. Arch Intern Med 2007;167:1379-1385.

29 Satchell SC, Tooke JE: What is the mechanism of microalbuminuria in diabetes: a role for the glomerular endothelium? Diabetologia 2008;51:714-725.

30 Prisby RD, Ramsey MW, Behnke BJ, Dominguez JM, Donato AJ, Allen MR, Delp MD: Aging Reduces Skeletal Blood Flow, Endothelium-Dependent Vasodilation, and NO Bioavailability in Rats. J Bone Miner Res 2007;22:1280-1288.

-31 Nakamura K, Tanaka Y, Saitou K, Nashimoto M, Yamamoto M: Age and Sex Differences in the Bone Mineral Density of the Distal Forearm Based on Health Check-up Data of 6343 Japanese. Osteoporos Int 2000;11:772-777.

-32 Fukui M, Ose H, Nakayama I, Hosoda H, Asano M, Kadono M, Mogami S-i, Hasegawa G, Yoshikawa T, Nakamura N: Association Between Urinary Albumin Excretion and Serum Dehydroepiandrosterone Sulfate Concentrations in Women With Type 2 Diabetes. Diabetes Care 2007;30:1886-1888.

-33 Ersoy F: Osteoporosis in the elderly with chronic kidney disease. Int Urol Nephrol 2007;39:321-331.

-34 Fried LF, Shlipak MG, Stehman-Breen C, Mittalhenkle A, Seliger S, Sarnak M, Robbins J, Siscovick D, Harris TB, Newman AB, Cauley JA: Kidney Function Predicts the Rate of Bone Loss in Older Individuals: The Cardiovascular Health Study. J Gerontol A Biol Sci Med Sci 2006;61:743-748.

35 Hsu C-Y, Cummings SR, McCulloch CE, Chertow GM: Bone mineral density is not diminished by mild to moderate chronic renal insufficiency. Kidney Int 2002;61:1814-1820.

-36 Ishani A, Paudel M, Taylor B, Barrett-Connor E, Jamal S, Canales M, Steffes M, Fink H, Orwoll E, Cummings S, Ensrud K: Renal function and rate of hip bone loss in older men: the Osteoporotic Fractures in Men Study. Osteoporos Int 2008;19:1549-1556.

-37 Vikas RD, Charles K, Gary S: Serum cystatin C is superior to serum creatinine as a marker of kidney function: A meta-analysis. Am J Kidney Dis 2002;40:221-226.

38 O'Riordan SE, Webb MC, Stowe HJ, Simpson DE, Kandarpa M, Coakley AJ, Newman DJ, Saunders JA, Lamb EJ: Cystatin C improves the detection of mild renal dysfunction in older patients. Ann Clin Biochem 2003;40:648-655.

-39 Van Den Noortgate NJ, Janssens WH, Delanghe JR, Afschrift MB, Lameire NH: Serum Cystatin C Concentration Compared with Other Markers of Glomerular Filtration Rate in the Old Old. J Am Geriatr Soc 2002;50:1278-1282.

-40 Klawansky S, Komaroff E, Cavanaugh PF, Mitchell DY, Gordon MJ, Connelly JE, Ross SD: Relationship between age, renal function and bone mineral density in the US population. Osteoporos Int 2003;14:570576.

-41 Ott SM: Review article: Bone density in patients with chronic kidney disease stages 4-5. Nephrology 2009;14:395-403.

42 Asomaning K, Bertone-Johnson ER, Nasca PC, Hooven F, Pekow PS: The Association between Body Mass Index and Osteoporosis in Patients Referred for a Bone Mineral Density Examination. J Women's Health 2006;15:1028-1034.

43 Morin S, Tsang JF, Leslie WD: Weight and body mass index predict bone mineral density and fractures in women aged 40 to 59 years. Osteoporos Int 2009;20:363-370.

44 Reid IR, Ames R, Evans MC, Sharpe S, Gamble G, France JT, Lim TM, Cundy TF: Determinants of total body and regional bone mineral density in normal postmenopausal women--a key role for fat mass. JCEM 1992;75:45-51.

45 Felson DT, Zhang Y, Hannan MT, Anderson JJ: Effects of weight and body mass index on bone mineral density in men and women: The framingham study. J Bone Miner Res 1993;8:567-573. 